\title{
Assessment of immune cells and function of the residual spleen after subtotal splenectomy due to splenomegaly in cirrhotic patients
}

\author{
Hai-Bo Chu', Ting-Guo Zhang ${ }^{2}$, Jian-Hua Zhao ${ }^{1}$, Feng-Guo Jian ${ }^{3}$, Yong-Bo Xu' ${ }^{1}$ Tao Wang ${ }^{4}$, Min Wang ${ }^{1}$, \\ Jin-Yuan Tang ${ }^{1}$, Hong-Jie Sun ${ }^{3}$, Kun Li ${ }^{1}$, Wen-Jun Guo ${ }^{2}$ and Xiao-Ji Zhu ${ }^{1 *}$
}

\begin{abstract}
Background: The spleen is thought to be central in regulating the immune system, a metabolic asset involved in endocrine function. Overwhelming postsplenectomy infection leads to a mortality rate of up to $50 \%$. However, there is still controversy on performing subtotal splenectomy as treatment of splenomegaly due to portal hypertension in cirrhotic patients. In the present study, immunocytes and the indexes of splenic size, hemodynamics, hematology and immunology in the residual spleen were analyzed to support subtotal splenectomy due to splenomegaly.
\end{abstract}

Results: In residual spleen, T lymphocytes mainly were focal aggregation in the periarterial lymphatic sheath. While B lymphocytes densely distributed in splenic corpuscle. In red pulp, macrophages were equally distributed in the xsplenic cord and adhered to the wall of splenic sinus with high density. The number of unit area $T$ and B lymphocytes of splenic corpuscle and marginal zone as well as macrophages of red pulp were obviously increased in the residual spleen, while the number of macrophages didn't be changed among the three groups in white pulp. While there were some beneficial changes (i.e., Counts of platelet and leucocyte as well as serum proportion of CD3+ T cells, CD4+ T cells, CD8+ T cells were increased markedly; serum levels of M-CSF and GM-CSF were decreased significantly; The proportion of granulocyte, erythrocyte, megakaryocyte in bone marrow were changed obviously; But serum IgA, IgM, IgG, Tuftsin level, there was no significant difference; splenic artery flow volume, portal venous diameter and portal venous flow volume, a significant difference was observed in residual spleen) in the clinical indices.

Conclusion: After subtotal splenectomy with splenomegaly due to portal hypertension in cirrhotic patients, the number of unit area $T$ and $B$ lymphocytes, and $M \varnothing$ in red pulp of residual spleen increased significantly. However, whether increase of $\mathrm{T}, \mathrm{B}$ lymphocytes and $\mathrm{M} \varnothing_{\mathrm{s}}$ in residual splenic tissue can enhance the immune function of the spleen, still need further research to confirm.

Keywords: Residual spleen, Splenomegaly, Portal hypertension, T, B lymphocytes, Macrophage, Immune

\section{Background}

The spleen is thought to be central in regulating the immune system, a metabolic asset involved in endocrine function [1]. Overwhelming postsplenectomy infection leads to a mortality rate of up to $50 \%$ [2]. How to reduce infectious incidence, maintain splenic immune function or conduct vaccination becomes a hot issue of innovation for surgeons

\footnotetext{
* Correspondence: xiaojizhu@163.com

${ }^{1}$ Center of General Surgery, The 89th Hospital of PLA, West Beigong Road 256, Weifang 261021, China

Full list of author information is available at the end of the article
}

[3,4]. Bierring et al [5] first reported the study about subtotal splenectomy carried out on the rats. Morgenstern et al [6] applied this surgical method in clinical practice. Later, a series of research has proven that approximately $25 \%$ of the residual splenic tissue can protect against pneumonococcus [7]. Phagocytic function of the splenic remnant after subtotal splenectomy was maintained, and the amounts of T, B cells remained indistinguishable from those in normal circumstances. In contrast, the phagocytic function of the splenic remnant after autotransplantation decreased, autotransplanted splenic 
remnants showed lower density and abnormal mixing of $B$ and $\mathrm{T}$ lymphocytes with widespread loss of follicles and periarterial lymphatic sheath (PALS) [8,9]. Clinical practice shows that subtotal splenectomy applies to splenic injuries, splenomegaly for hematological diseases and portal hypertension [10-12].

There is still controversy on performing subtotal splenectomy as treatment of splenomegaly due to portal hypertension in cirrhotic patients. Advocates for splenectomy believe that, with fibrosis and little immune function in splenomegaly, recurrence of splenomegaly and hypersplenism may happen in residual spleen [13]. However, advocates inclined to preserve spleen argue that subtotal splenectomy may reduce portal venous pressure, correct hypersplenism and retain the immune function of spleen-which means killing two birds with one stone [14]. Subtotal splenectomy includes two ways, i.e., with preserving the upper pole and the lower pole of the spleen supplied by the gastrosplenic vessels, spleno-omental and spleno-coloic vessels $[14,15]$. In the present study, immunocytes and the indexes of splenic size, hemodynamics, hematology and immunology in the residual spleen were analyzed to support subtotal splenectomy due to splenomegaly in cirrhotic patients.

\section{Results}

Spleen organization were obtained by operating formed splenomegaly group. Patients who had spleen puncture to check for spleen organization 8 years after surgery formed the residual spleen group. Patients who underwent splenectomy but who did not have splenomegaly formed the control group.

In residual spleen group, $\mathrm{T}$ lymphocytes mainly were focal aggregation in the periarterial lymphatic sheath (PALS), and sporadic or focal distribution in red pulp. while B lymphocytes densely distributed in splenic corpuscle, but was sporadic in red pulp, and its volume was slightly smaller, and dyed deeply (Figure 1A, B). In the splenomegaly group, splenic corpuscular atrophy, PALS narrowed, and their number decreased, splenic sinus stenosis and stasis, splenic cord thickened, densely distribution area of $\mathrm{T}$ cells zone reduced, density of $\mathrm{B}$ cell around the splenic corpuscular decreased, and B cells in red pulp is slightly less, $\mathrm{T}$ and $\mathrm{B}$ lymphocytes increased in size, staining lightly (Figure $1 C, D$ ). In the control group, $\mathrm{T}$ cells densely distributed in PALS, sparsely in red pulp (Figure 1E), B cells were densely distributed in splenic corpuscle, and were scattered in red pulp (Figure 1F).

In the residual spleen group, $M \emptyset_{\mathrm{s}}$ well-distributed in the splenic cord and adhered to the wall of splenic sinus in red pulp, with high density and dying deeply. In white pulp, MØs were scattered in splenic corpuscle, and were concentrated obviously in MZ, and may see larger $M \varnothing$ (Figure 1G, H). In the splenomegaly group, MØs in the red pulp distributed loosely and irregularly, density obviously lower, understained in color, distribution of MØs in splenic corpuscular and $\mathrm{MZ}$ of white pulp was the same as residual spleen (Figure 1I, J). In the control group, MØs equally distributed in splenic cord and adhered to the wall of splenic sinus in red pulp, with high density and dying deeply; distribution of $M \varnothing_{\text {s in splenic }}$ corpuscular and $\mathrm{MZ}$ of white pulp was the same as residual spleen (Figure 1K, L).

Residual spleen was preserved about $11 \times 7 \times 4 \mathrm{~cm}$ on operation. It was alive that was confirmed by $\mathrm{CT}$ scan, and still had phagocytosis via splenic scintigraphy with ${ }^{99 \mathrm{~m}} \mathrm{Tc}$ sulfur colloid after eight years (Figure 2A-E).

\section{Quantitative analysis of T, B lymphocytes, Møs}

For $\mathrm{T}$ and $\mathrm{B}$ lymphocytes, significant differences in residual spleen group as compared with splenomegaly group and control group were observed $(p<0.05)$, and a significant difference was also observed between splenomegaly group and congtrol group $(p<0.05)$ (Table 1$)$.

In red pulp, significantly higher the counts of $M \varnothing_{s}$ in the residual spleen group as compared with splenomegaly group and control group was observed $(p<0.05)$. A significant difference between splenomegaly group and control group was also seen $(p<0.05)$. However, significant difference was not observed among the three groups in white pulp (splenic corpuscle and MZ) $(p>0.05)$ (Table 2).

\section{Change of splenic size, hemodynamics, hematological, immunological indices between residual spleen and splenomegaly}

With respect to splenic length, splenic thickness, splenic square area, splenic artery flow volume, portal venous diameter and portal venous flow volume, a significant difference was observed between residual spleen groups and splenomegaly groups $(p<0.001)$. Counts of platelet and leucocyte in residual spleen were increased markedly compared with splenomegaly groups, and a significant difference was observed $(p<0.001)$. With respect to IgA, IgM, IgG, Tuftsin level, there was no significant difference between residual spleen groups and splenomegaly groups $(p>0.05)$ (Table 3$)$.

\section{Change of serum proportion of CD3+ T cells, CD4+ T cells, CD8+ T cells, serum levels of M-CSF and GM-CSF as well as the proportion of granulocyte, erythrocyte, megakaryocyte in bone-marrow indices between residual spleen and splenomegaly}

Serum proportion of CD3+ T cells, CD4+ T cells, CD8+ T cells were in residual spleen increased markedly compared with splenomegaly groups, and a significant difference was observed $(p<0.05)$ (Table 4$)$. Serum levels of M-CSF and GM-CSF were decreased significantly, there was a 


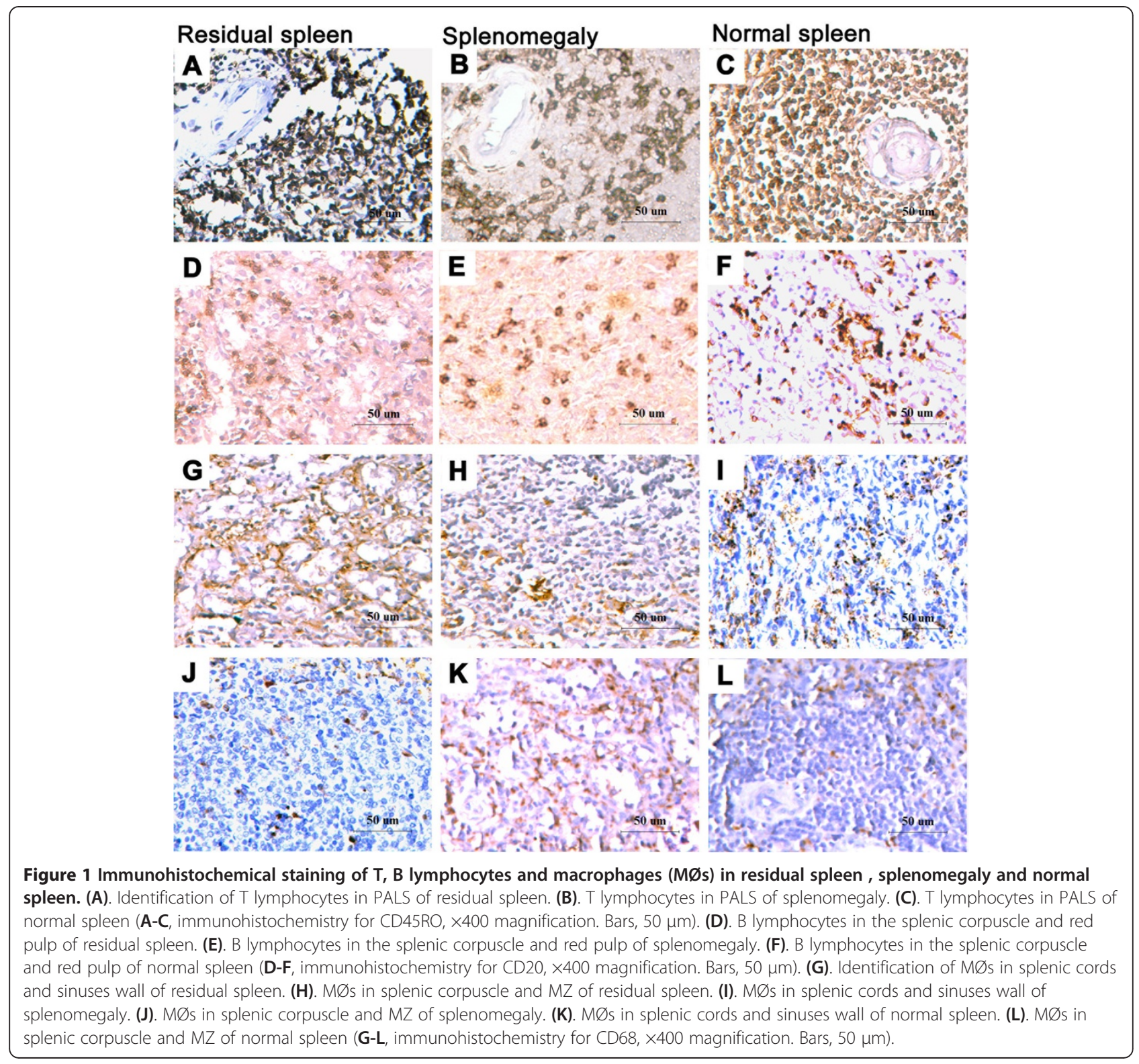

significant difference between residual spleen groups and splenomegaly groups $(p<0.05)$ (Table 5$)$. The proportion of granulocyte, erythrocyte, megakaryocyte in bone marrow were changed obviously, and a significant difference was seen $(p<0.05$ and $p<0.01, p<0.001$ or $p>0.05)$ (Table 6).

\section{Discussion}

The spleen is a highly compartimentalized organ, and each compartment has its own structure, cell population, and functions [16]. White pulp PALS contains a large number of $\mathrm{T}$ lymphocytes, red pulp reticular meshwork contains MØs and abundant erythrocytes, and MZ is divided into an inner and an outer compartment by a special type of fibroblasts, in which a variety of cell types are combined, such as different types $M \varnothing_{\mathrm{s}}$ at the inner border, and to a lesser extent, the MZ B cells. For other cell types-T lymphocytes, small B cells, and dendritic cells-the MZ is only a temporary residence $[17,18]$. The splenic compartments show different kinetics for migrating lymphocytes [19]. Splenic MZ is the pathway of $\mathrm{T}$ and $\mathrm{B}$ lymphocytes migration, and contains accessory cells (MZ macrophages and interdigitating cells) associated with cell migration $[20,21]$. It has been reported that the splenic MZ MØ population has its special function, controlling the retention and trafficking of B lymphocytes, and interacts with apoptotic material entering the spleen from circulation to minimize the immunogenicity of autoantigens [22,23]. MØs display remarkable plasticity and can change their physiology in response to environmental 

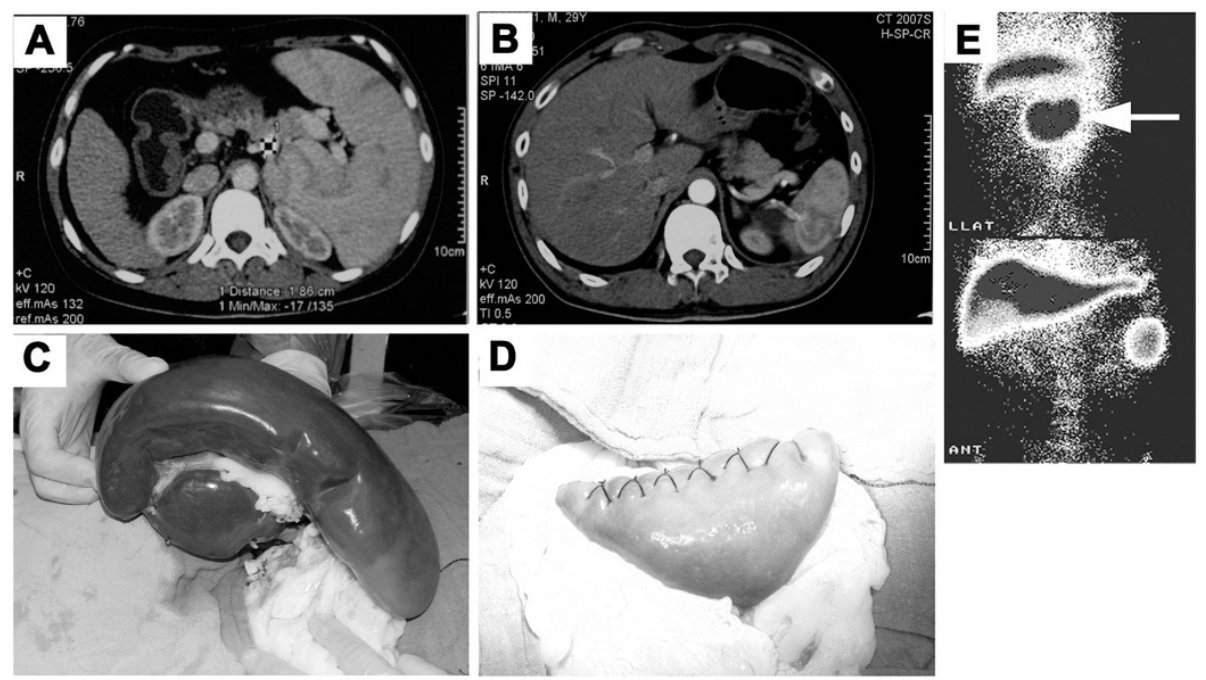

Figure $\mathbf{2}$ Images of clinical data. (A\&B). CT images of preoperative and postoperative eight years. (C\&D). Intraoperative splenomegaly and residual spleen. (E). Splenic scintigraphy with ${ }^{99 \mathrm{~m}} \mathrm{Tc}$ sulfur colloid after eight years (residual, arrow).

cues, and these changes can give rise to different populations of cells with distinct function [24]. It can be seen that the splenic white pulp and MZ were is a gathering area of mass T, B lymphocytes and specific functional MØs , the core parts of the splenic immune function was called, and its range was depended the number and functions of T, B lymphocytes, and MØs, so it becomes the portal of the splenic immune function.

When splenomegaly, there was hyperplasia and hyperactivation of the splenic lymphoid tissue, and CD4+/CD8+ T cell ratios increased, the proportion of $\mathrm{CD} 8+\mathrm{T}$ cells decreased, immature B cells or immunoblasts will proliferate in response to antigenic stimuli $[25,26]$. Yamamoto and $\mathrm{Li}$ et al. reported that the volume of red pulp of the spleen with portal hypertension was increased in a unit area, the white pulp was scanty of $T$ and $B$ lymphocytes and decreased in a unit area, but it was increased in the whole spleen. Although proliferation and distribution may be disordered, they believe that the spleen with portal hypertension may still have immune function $[27,28]$. Animal experiments in rabbits and mice, Histological study showed both the total number of cells and the number of cells per gram of tissue were significantly reduced, and antibody response was poorly in

Table 1 Number of T and B Lymphocytes in Splenic Tissue $(n=13$, means \pm SD)

\begin{tabular}{lll}
\hline & $\begin{array}{l}\text { T Lymphocytes } \\
\text { (per } 1 \mathbf{1 0}^{-\mathbf{5}} \text { pixel area) }\end{array}$ & $\begin{array}{l}\text { B Lymphocytes } \\
\text { (per } 10^{-5} \text { pixel area) }\end{array}$ \\
\hline Residual spleen & $59.77 \pm 9.43^{\mathrm{a}}$ & $10.82 \pm 1.94^{\mathrm{a}}$ \\
Splenomegaly & $34.72 \pm 3.50^{\mathrm{b}}$ & $2.37 \pm 0.66^{\mathrm{b}}$ \\
Control & $48.23 \pm 14.87$ & $6.84 \pm 0.81$ \\
\hline
\end{tabular}

Compared with the splenomegaly and control group, ${ }^{\mathrm{a}} P<0.05$; compared with the control group, ${ }^{\mathrm{b}} P<0.05$. autotransplantation after splenectomy. There was a substantial reduction in the percentage of some of the cells examined (CD4+ and CD8+ T lymphocytes subsets), but not all (B lymphocytes, ED1+ and ED2+ macrophages, $\mathrm{OX} 2+$ and OX6+ cells). This results suggests that the regenerated spleen can maintain $\mathrm{T}$ cell number, but cannot compensate for the immunological function of the original one,especially host resistance to infection $[29,30]$. Li et al. reported the relative quantity of MØs per unit weight of splenomegaly decreased significantly, however, total quantity of MØs increased significantly, so rhe results suspect the latter was relatively increased due to enlargement of splenic volume [31]. Whereafter found that the phagocytosis rate and phagocytic capacity of $\mathrm{M} \varnothing$ in splenomegaly was more higher than the control group, nevertheless this prompt that macrophage phagocytosis may be positively correlated with the degree of hypersplenism [32]. A group of researchers show that, in the patients of splenomegaly with immune thrombocytopenia,the phagocytosis rate in splenic macrophages positively correlated with the ratio of Th1/Th2, but negatively correlated with percentage of Th2 cells [33]. Thus, splenomegaly and hyperdynamic

Table 2 Macrophage counts in splenic tissue $(n=13$, means \pm SD)

\begin{tabular}{lll}
\hline & \multicolumn{2}{l}{ Macrophage counts } \\
\cline { 2 - 3 } & $\begin{array}{l}\text { Rep Pulp (per } \mathbf{1 0}^{\mathbf{- 5}} \text { pixel } \\
\text { area) }\end{array}$ & $\begin{array}{l}\text { White Pulp (per high-power } \\
\text { field) }\end{array}$ \\
\hline $\begin{array}{l}\text { Residual } \\
\text { spleen }\end{array}$ & $31.09 \pm 9.73^{\mathrm{a}}$ & $16.69 \pm 4.37$ \\
Splenomegaly & $4.20 \pm 0.88^{\mathrm{b}}$ & $15.77 \pm 5.00$ \\
Control & $7.46 \pm 0.86$ & $14.46 \pm 2.90$ \\
\hline
\end{tabular}

Compared with the splenomegaly and control group, ${ }^{\mathrm{a}} P<0.05$; compared with the control group, ${ }^{\mathrm{b}} \mathrm{P}<0.05$. 
Table 3 Comparison of splenic size, hemodynamic, hematological and immunological indices between the two groups $(n=13$, means \pm SD)

\begin{tabular}{llll}
\hline & Splenomegaly & $\begin{array}{l}\text { Residual } \\
\text { spleen }\end{array}$ & $P$ value \\
\hline Splenic length $(\mathrm{cm})$ & $47.77 \pm 4.85$ & $11.31 \pm 1.11$ & $<0.01$ \\
Splenic thickness $(\mathrm{cm})$ & $10.00 \pm 1.68$ & $3.62 \pm 0.51$ & $<0.01$ \\
Splenic square area $\left(\mathrm{cm}^{2}\right)$ & $387.20 \pm 101.09$ & $33.05 \pm 7.31$ & $<0.01$ \\
Splenic artery flow & $7.51 \pm 0.56$ & $2.91 \pm 0.03$ & $<0.01$ \\
volume (ml/kg.min) & & & \\
Portal venous & $1.42 \pm 0.04$ & $1.15 \pm 0.04$ & $<0.01$ \\
diameter (cm) & & & \\
Portal venous flow & $19.72 \pm 0.37$ & $16.46 \pm 0.37$ & $<0.01$ \\
volume (ml/kg.min) & & & \\
Leucocytes $\left(\times 10^{9} / \mathrm{L}\right)$ & $2320.77 \pm 322.22$ & $4261.54 \pm 276.07$ & $<0.01$ \\
Platelets $\left(\times 10^{9} / \mathrm{L}\right)$ & $51.30 \pm 5.98$ & $218.77 \pm 28.69$ & $<0.01$ \\
IgA $(\mathrm{g} / \mathrm{L})$ & $4.14 \pm 0.34$ & $4.34 \pm 0.07$ & $>0.05$ \\
IgM $(\mathrm{g} / \mathrm{L})$ & $3.04 \pm 0.21$ & $3.15 \pm 0.10$ & $>0.05$ \\
IgG $(\mathrm{g} / \mathrm{L})$ & $20.15 \pm 1.32$ & $21.21 \pm 1.40$ & $>0.05$ \\
Tuftsin $(\mu \mathrm{g} / \mathrm{L})$ & $603 \pm 162$ & $656 \pm 147$ & $>0.05$ \\
\hline
\end{tabular}

blood can cause the splenic structure change, the numbers of $\mathrm{T}$ and $\mathrm{B}$ lymphocytes as well as $\mathrm{MØs}$ in unit area or volume decreased. This finding suggested that splenic tissue structure is closely correlated with the quantity of T, B lymphocytes and MØs, while whether remodeling of these cells would affect the splenic immune function still remained controversy.

In this present study, the histological features of the residual spleens which were reserved was discovered as follows: Firstly, the size of the residual spleen was similar to normal. Secondly, the number of splenic corpuscle and PALS increased, the morphous of the splenic sinus approximated to normal, structure compact. Thirdly, T lymphocytes shaped focal aggregation in the PALS. Fourthly, B lymphocytes densely distributed in splenic corpuscle. Fifthly, МØs were evenly distributed in the splenic cord and adhered to the wall of splenic sinus in red pulp, increased density and dyed deeply, they were diffused distribution in splenic corpuscle of white pulp, and more densely distributed in MZ, with larger cell volume. Quantitative analysis of the cells showed that Significantly higher counts of unit area $\mathrm{T}$ and B lymphocytes in the residual spleen group obviously increased as compared

Table 4 Comparison of serum proportion of CD3 $+\mathrm{T}$ cells, CD4 + T cells, CD8 + T cells between the two groups ( $n=13, \%$, means $\pm S D$ )

\begin{tabular}{llll}
\hline & Splenomegaly & Residual spleen & P value \\
\hline CD3+ T cells & $56.20 \pm 2.90$ & $65.68 \pm 2.30$ & $<0.001$ \\
CD4+ T cells & $32.90 \pm 2.30$ & $40.00 \pm 2.90$ & $<0.001$ \\
CD8+ T cells & $3.26 \pm 0.20$ & $24.60 \pm 2.40$ & $<0.001$ \\
\hline
\end{tabular}

Table 5 Comparison of serum levels of M-CSF and GMCSF between the two groups ( $n=13, n g / m l$, means $\pm S D$ )

\begin{tabular}{llll}
\hline & Splenomegaly & Residual spleen & P value \\
\hline M-CSF & $3.19 \pm 0.19$ & $1.86 \pm 0.18$ & $<0.001$ \\
GM-CSF & $2.07 \pm 0.18$ & $0.39 \pm 0.10$ & $<0.001$ \\
\hline
\end{tabular}

with splenomegaly group and control group, while splenomegaly group significantly decreased than control group. Significantly higher number of unit area MØs of red pulp in the residual spleen group obviously increased as compared with splenomegaly group and control group, but splenomegaly group significantly less than control group. In addition, hemodynamics of the residual spleen and portal vein improved, amounts of platelet and leucocyte rose to normal, and there were no significant changes in immunological indexes. Results suggest that subtotal splenectomy may reduce portal venous pressure, correct hypersplenism and retain immune function of spleen. Our study demonstrated that the distribution characteristics of $M \varnothing$ in red pulp resembles Vasco's report [34]. MZ MØs are larger and morphologically distinct from other macrophages $[35,36]$. Our results suggest that high hemodynamic bood plays an crucial and initial role in adaptive changes of splenomegaly tissue. Splenic histological remodeling must be involed in migration and redistribution of cells, when

Table 6 Comparison of the proportion of granulocyte, erythrocyte, megakaryocyte in bone marrow between the two groups $(n=13, \%$, means \pm SD)

\begin{tabular}{|c|c|c|c|}
\hline & Splenomegaly & $\begin{array}{l}\text { Residual } \\
\text { spleen }\end{array}$ & $P$ value \\
\hline Myeloblast & $0.38 \pm 0.04$ & $0.35 \pm 0.03$ & $>0.05$ \\
\hline Promyelocyte & $1.60 \pm 0.12$ & $1.70 \pm 0.15$ & $>0.05$ \\
\hline Neutrophilic myelocyte & $6.62 \pm 0.61$ & $7.84 \pm 0.59$ & $<0.001$ \\
\hline Neutrophilic metamyelocyte & $9.11 \pm 0.81$ & $12.81 \pm 0.56$ & $<0.001$ \\
\hline Stabnuclear neutrophil & $15.52 \pm 1.28$ & $18.38 \pm 0.48$ & $<0.001$ \\
\hline $\begin{array}{l}\text { Neutrophilic granulocyte } \\
\text { segmented form }\end{array}$ & $6.57 \pm 1.18$ & $16.17 \pm 1.27$ & $<0.001$ \\
\hline $\begin{array}{l}\text { Eosinophile granulocyte } \\
\text { (per stage) }\end{array}$ & $6.06 \pm 1.43$ & $7.26 \pm 1.86$ & $>0.05$ \\
\hline Basophilic leukocyte (per stage) & $0.04 \pm 0.03$ & $0.22 \pm 0.18$ & $>0.05$ \\
\hline Macroblast of Naegeli & $0.67 \pm 0.13$ & $0.30 \pm 0.07$ & $<0.001$ \\
\hline Basophilic erythroblast & $1.99 \pm 0.17$ & $0.79 \pm 0.84$ & $<0.001$ \\
\hline Polychromatophilic erythroblast & $20.15 \pm 1.37$ & $5.81 \pm 2.27$ & $<0.001$ \\
\hline Acidophilic normoblast & $13.11 \pm 2.43$ & $7.11 \pm 1.93$ & $<0.001$ \\
\hline Megakaryoblast & $0.44 \pm 0.17$ & 0 & $<0.001$ \\
\hline Immature megakaryoblast & $2.47 \pm 1.83$ & $0.20 \pm 0.05$ & $<0.001$ \\
\hline Granula megakaryoblast & $61.56 \pm 5.85$ & $22.88 \pm 1.59$ & $<0.001$ \\
\hline Maturity form megakaryoblast & $26.32 \pm 2.56$ & $71.13 \pm 3.73$ & $<0.001$ \\
\hline Naked nucleus & $7.97 \pm 5.32$ & $4.66 \pm 5.25$ & $>0.05$ \\
\hline
\end{tabular}


hemodynamic blood reversed in residual spleen. Quantity of $\mathrm{T}$ and $\mathrm{B}$ lymphocytes per unit area in their respective function zone of residual spleen increased, that may enhance the ability of immune response in the residual spleen. $M \varnothing$ accumulation remodeling in red pulp of the residual spleen indrectly reflected that hematopoietic function of red pulp enhanced. Splenic marginal zone was the pathway through which lymphocytes migrated from the white pulp into red pulp, where lymphocytes closely contacted with MØs and interdigitating cells, and participated in the immune response after being activated $[21,37]$. There was no significant difference in counts of MØs in white pulp and MZ among the three groups, indicating that number of $M \varnothing$ involved in immune response didn't decrease due to fibrosis in groups of residual spleen and splenomegaly. Besides, after subtotal splenectomy with splenomegaly due to portal hypertension in cirrhotic patients, serum proportion of CD3+ $\mathrm{T}$ cells, CD4+ T cells, CD8+ T cells were increased markedly and serum levels of M-CSF and GM-CSF were decreased significantly. Results suggest that residual splenic tissue can enhance immune reaction and weaken inflammatory reaction. The proportion of granulocyte, erythrocyte, megakaryocyte in bone marrow were changed obviously. Results suggest that the spleen inhibited the bone marrow, and haemocyte function was removed. Our previous study found that there was no significant difference in the content of collagen, elasticity and reticular fiber between the residual spleen and splenomegaly. The ultra cell structure of the residual spleen was similar to that in normal spleen, suggesting fibrosis presented and cell morphology was normal in residual spleen. The change of immune cells and heamodynamic, hematological and immunological indices proves that it is feasible and necessary to implement subtotal splenomegaly for portal hypertension. We believe that the residual spleen has its special artery blood-supply, maintaining the tissue structure and cell function of the spleen on one hand, and improving the status of highpressure and hypoxia in the spleen on the other hand. Rectification of hypersplenism, extrication from high-pressure and cease of fibrosis in spleen was all conducive to accumulation, growth and performance of immune function of $\mathrm{T}, \mathrm{B}$ lymphocytes and MØs in white pulp and MZ of the spleen. These discoveries of ours have considerable clinical guiding significance for deciding between "exsect" and "reserve" for splenomegaly due to portal hypertension. Cores function of the spleen is immune function, and alteration of immunocytes in residual spleen can reveal regularity of inherent function in fibrosis spleen. However, whether increase of T, B lymphocytes and MØs in residual splenic tissue can enhance the immune function of the spleen, still need further research to confirm. Because our sample size was small, a multi-centre large-sample study is needed. Nevertheless, this study provided interesting information: after subtotal splenectomy with splenomegaly due to portal hypertension in cirrhotic patients, the residual spleen still has immune function.

\section{Conclusions}

Subtotal splenectomy for splenomegaly due to portal hypertension results in a significant increase in the number per unit area of $\mathrm{T}$ cells and $\mathrm{B}$ cells, and in the number of macrophages in red pulp of the residual spleen.

\section{Methods}

Ethical approval of the study protocol (No. 5986) was approved by the Human Research Ethics Committee of the Weifang Medical University. All individuals provided written informed consent before being included in the study.

\section{Study population}

Our studies relating to subtotal splenectomy started in 1984. Up to 2012, we have conducted 752 operations of subtotal splenectomy (preserving the lower pole, normal spleen size of splenic tissue, splenic omentum and splenocolic vessels for the purpose of blood-supply), with 117 cases for splenic trauma and 635 for splenomegaly due to portal hypertension. Thirteen tissue samples were collected from patients in the 89th Hospital of the People's Liberation Army (Weifang, China). thirteen cases (7 males and 6 females; mean age, 31 (26-36) years)) with splenomegaly due to portal hypertension who had received subtotal splenectomy plus fixation of the posterior sternal omentum majus were included in this group. Patients were confirmed to have cirrhosis after hepatitis-B infection, HBV-DNA was negative and were classified as class A or B according to the Child-Pugh classification. Cirrhosis was accompanied by hypersplenism with light or moderate varicose veins of the lower esophagus, and the fibrosis level in the spleen was III. Color Doppler ultrasound was used before surgery and 8 years after surgery to measure the size of the spleen. The preoperative long-diamater was $48 \pm 5 \mathrm{~cm}$, the transverse diameter was $30 \pm 4 \mathrm{~cm}$, and the pachy- diamater was $10 \pm 2 \mathrm{~cm}$. The postoperative long-diameter was $11 \pm 1 \mathrm{~cm}$, the transverse diameter was $7 \pm 1 \mathrm{~cm}$, and the pachy-diameter was $4 \pm 1 \mathrm{~cm}$. Spleen organization were obtained by operating formed splenomegaly group. Patients who had spleen puncture to check for spleen organization 8 years after surgery formed the residual spleen group. Thirteen cases ( 7 males 6 females; mean age, 30 (28-37) years) who underwent splenectomy but who did not have splenomegaly formed the control group. Guided by color Doppler ultrasound, hollow-needle biopsy was used for to obtain samples of residual splenic tissue [38]. 


\section{Methods}

Thirty nine tissue samples were collected. Specimens were fixed in $10 \%$ formalin, dehydrated, embedded and sliced. Each specimen was made into 15 slices (5 slices per group). $\mathrm{PH}$ 8.5, EDTA antigen retrieval, 3\% peroxidemethano and goat serum closed by SP immunohistochemical method. CD45RO antibody (Sunbio, Shanghai, China) was used to specifically stain T-cells, and CD20 antibody (Sunbio) was used to identify B-cells, whereas CD68 antibody (Sunbio) was used to identify macrophages (MØs). Samples were then diluted in phosphate-buffered saline (PBS) and colored with 3,3-diaminobenzidine (DAB). Dehydration, clearing, and mounting with neutral gums was carried out. A negative control group was obtained using the same steps as described above, but instead the antibody was replaced by PBS. After staining, slices were observed under a light microscope (BX51; Olympus, Tokyo, Japan) for histomorphological analyses. Under light microscope $(\times 400)$, Image-Pro Plus (Media Cybernetics, Silver Spring, MD) was used to calculate the the counts of T, B lymphocytes and MØs, respectively. Three effective visual field of each section were selected, calculated the counts of positive T, B lymphocytes per pixel area in aim area, and then counted the mean (pixel density was 2.88 pixels $/ \mu \mathrm{m})[39,40]$. Selection criteria of measuring region: T lymphocytes' measurement area was PALS, and B lymphocytes' measurement area, including marginal zone (MZ) and part of red pulp. And the measuring region of $M \emptyset \mathrm{s}$ included red pulp and the splenic corpuscular and MZ of white pulp.

In addition, patients underwent complete physical examination before and after the operation, which included abdominal ultrasonography (splenic size: splenic length, splenic thickness, splenic square area; hemodynamics: splenic artery flow volume, portal venous diameter, portal venous flow volume), abdominal CT scan, splenic scintigraphy with ${ }^{99 \mathrm{~m}}$ Tc sulfur colloid, laboratory hematological (platelets, leucocytes) immunological (serum IgA, IgM, IgG, Tuftsin, CD3+ T cells, CD4+ T cells, CD8+ T cells, M-CSF, GM-CSF) and bone-marrow evaluation.

\section{Statistical analyses}

Data analyses were carried out using SPSS 17.0 (SPSS Inc., Chicago, Illinois). All values are means \pm standard deviation (SD). Groups were compared by the t-test. $P<0.05$ was considered significant.

\section{Competing interests}

The authors declare that they have no competing interests.

\section{Authors' contributions}

T-GZ performed flow cytometry analysis, analyzed data, wrote the paper. F-GJ, Y-BX, KL, and H-JS collected and analyzed clinical data. TW and MW performed flow cytometry analysis, analyzed data, made graphs. W-JG designed study, analyzed data. J-HZ and J-YT completed statistical analysis. H-BC and X-JZ designed study, analyzed data, wrote the paper. All authors read and approved the final manuscript.

\section{Acknowledgments}

We thank Lingyan Ju, Zehui Jiang for technical assistance. We are also grateful to the staff of the center of general surgery, the 89th Hospital of PLA.

\section{Author details}

${ }^{1}$ Center of General Surgery, The 89th Hospital of PLA, West Beigong Road 256, Weifang 261021, China. ${ }^{2}$ Department of Pathology, Weifang Medical University, Weifang, China. ${ }^{3}$ Department of General Surgery, Changyi People's Hospital, Weifang, China. ${ }^{4}$ Departments of Pathology, The 89th Hospital of PLA, Weifang, China.

Received: 15 May 2014 Accepted: 22 September 2014

Published online: 08 October 2014

\section{References}

1. Tarantino G, Savastano S, Capone D, Colao A: Spleen: a new role for an old player? World J Gastroenterol 2011, 17:3776-3784.

2. Jones P, Leder K, Woolley I, Cameron P, Cheng A, Spelman D: Postsplenectomy infection-strategies for prevention in general practice. Aust Fam Physician 2010, 39:383-386.

3. Petroianu A, Resende V, Silva R: Late postoperative follow-up of patients undergoing subtotal splenectomy. Clinics (Sao Paulo) 2005, 60:473-478.

4. Coignard-Biehler $H$, Lanternier F, Hot A, Salmon D, Berger A, de Montalembert M, Suarez F, Launay O, Lecuit M, Lortholary O: Adherence to preventive measures after splenectomy in the hospital setting and in the community. J Infect Public Health 2011, 4:187-194.

5. Blerring F, Grunnet I: Quantitative bone marrow studies in the rat following a combination of subtotal splenectomy, total thymectomy and extensive removal of lymph nodes. Acta Anat (Basel) 1964, 59:182-187.

6. Morgenstern L, Kahn F, Weinstein I: Subtotal splenectomy in myelofibrosis Surgery 1966, 60:336-339.

7. Goldthorn JF, New BA, Schwartz AD: The protection of small amounts of splenic tissue against intravenous pneumococcal challenge following subtotal splenectomy. J Surg Oncol 1981, 17:145-149.

8. Malangoni MA, Dawes LG, Droege EA, Rao SA, Collier BD, Almagro UA: Splenic phagocytic function after partial splenectomy and splenic autotransplantation. Arch Surg 1985, 120:275-278.

9. Dugan MC, Grogan TM, Witte MH, Rangel C, Richter L, Witte CL, Van Wyck DB: Immunoarchitecture of the regenerating rat spleen: effects of partial splenectomy and heterotopic autotransplantation. Scan Electron Microsc 1986, (Pt 2):607-613.

10. Resende $V$, Petroianu $A$ : Functions of the splenic remnant after subtotal splenectomy for treatment of severe splenic injuries. Am J Surg 2003, 185:311-315.

11. Bader-Meunier B, Gauthier F, Archambaud F, Cynober T, Miélot F, Dommergues JP, Warszawski J, Mohandas N, Tchernia G: Long-term evaluation of the beneficial effect of subtotal splenectomy for management of hereditary spherocytosis. Blood 2001, 97:399-403.

12. Petroianu A, Da Silva RG, Simal CJ, De Carvalho DG, da Silva RA: Late postoperative follow-up of patients submitted to subtotal splenectomy. Am Surg 1997, 63:735-740.

13. Andraus W, Pinheiro RS, Haddad LB, Herman P, D'Albuquerque LA: The best approach for splenectomy in portal hypertension. Surgery 2011, 149:853.

14. Li E, Zhao L, Zhu L, Lin A, Ge L, Wang F, Shi B: Treating portal hypertension by subtotal splenectomy with retroperitoneal splenic transposition and devascularization: clinical study. Zhonghua Wai Ke Za Zhi 1998, 36:333-335.

15. Petroianu A, Resende V, Da Silva RG: Late follow-up of patients submitted to subtotal splenectomy. Int Surg 2006, 4:172-178.

16. Elmore SA: Enhanced histopathology of the spleen. Toxicol Pathol 2006, 34:648-655.

17. Steiniger $B, B$ arth $P$, Hellinger $A$ : The perifollicular and marginal zones of the human splenic white pulp: do fibroblasts guide lymphocyte immigration? Am J Pathol 2001, 159:501-512. 
18. Bajenoff M, Glaichenhaus N, Germain RN: Fibroblastic reticular cells guide T lymphocyte entry into and migration within the splenic T cell zone. J Immunol 2008, 181:3947-3954.

19. Pabst $\mathrm{R}$, Westermann J: The role of the spleen in lymphocyte migration. Scanning Microsc 1991, 5:1075-1079.

20. Mina-Osorio P, Rosas-Ballina M, Valdes-Ferrer SI, Al-Abed Y, Tracey KJ, Diamond B: Neural signaling in the spleen controls B-cell responses to blood-borne antigen. Mol Med 2012, 18:618-627.

21. Brelińska R, Pilgrim C: Macrophages and interdigitating cells; their relationship to migrating lymphocytes in the white pulp of rat spleen. Cell Tissue Res 1983, 233:671-688.

22. Karlsson MC, Guinamard R, Bolland S, Sankala M, Steinman RM, Ravetch JV: Macrophages control the retention and trafficking of B lymphocytes in the splenic marginal zone. J Exp Med 2003, 198:333-340.

23. McGaha TL, Chen Y, Ravishankar B, van Rooijen N, Karlsson MC: Marginal zone macrophages suppress innate and adaptive immunity to apoptotic cells in the spleen. Blood 2011, 117:5403-5412.

24. Mosser DM, Edwards JP: Exploring the full spectrum of macrophage activation. Nat Rev Immunol 2008, 8:958-969.

25. Tokushige K, Hirose S, Nishimura H, Fujimori M, Yamauchi K, Obata H, Futagawa S, Shirai T: Abnormal T cell activation and skewed T cell receptor $\mathrm{V}$ beta repertoire usage in Japanese patients with idiopathic portal hypertension. Clin Immunol Immunopathol 1995, 75:206-213.

26. Mejias M, Garcia-Pras E, Gallego J, Mendez R, Bosch J, Fernandez M: Relevance of the mTOR signaling pathway in the pathophysiology of splenomegaly in rats with chronic portal hypertension. $J$ Hepatol 2010, 52:529-539.

27. Yamamoto K: Morphological studies of the spleen in idiopathic portal hypertension (so-called Banti's syndrome without liver cirrhosis) using light microscopy, scanning electron microscopy and histometry. Acta Pathol Jpn 1979, 29:1-19.

28. Li ZF, Zhang S, LV GB, Huang Y, Zhang W, Ren S, Yang J, Dang SS: Changes in count and function of splenic lymphocytes from patients with portal hypertension. World J Gastroenterol 2008, 14:2377-2382.

29. Tang WH, Wu FL, Huang MK, Friess H: Splenic tissue autotransplantation in rabbits: no restoration of host defense. Langenbecks Arch Surg 2003, 387:379-385.

30. Smith E, De Young NJ, Drew PA: Immune cell subpopulations in regenerated splenic tissue in rats. Aust N Z J Surg 1999, 69:522-525.

31. Li ZF, Gao J, Zhang S, Zhang Y, Sun Y, Su Q: The observation of quantity and phagocytosis of splenic macrophages in patients with portal hypertension-associated hypersplenism. Chin J Exp Surg 2006, 23:1288-1290.

32. Li ZF, Zhang S: Changes in splenic macrophage function of hypersplenism due to portal hypertension. Zhonghua Wai Ke Za Zhi 2009, 47:89-91.

33. Chen X, Chen S, Li C, Zhu Y, Peng B: Skewed T-cell subsets and enhanced macrophages phagocytosis in the spleen of patients with immune thrombocytopenia failing glucocorticoids. Int J Hematol 2011, 94:248-254.

34. Guisado Vasco P, Villar Rodriguez JL, Ibañez Martínez J, González Cámpora R, Galera Davidson H: Immunohistochemical organization patterns of the follicular dendritic cells, myofibroblasts and macrophages in the human spleen-new considerations on the pathological diagnosis of splenectomy pieces. Int J Clin Exp Pathol 2009, 3:189-202.

35. Humphrey JH, Grennan D: Different macrophage populations distinguished by means of fluorescent polysaccharides. Recognition and properties of marginal-zone macrophages. Eur J Immunol 1981 11:221-228.

36. Steiniger B, Barth P, Herbst B, Hartnell A, Crocker PR: The species-specific structure of microanatomical compartments in the human spleen: strongly sialoadhesin-positive macrophages occur in the perifollicular zone, but not in the marginal zone. Immunology 1997, 92:307-316.

37. Brozman M: Anatomical pathways from the white to the red pulp in the human spleen. Acta Anat (Basel) 1985, 121:189-193.

38. Gomez-Rubio M, Lopez-Cano A, Rendon P, Munoz-Benvenuty A, Macias M, Garre C, Segura-Cabral JM: Safety and diagnostic accuracy of percutaneous ultrasound-guided biopsy of the spleen: a multicenter study. J Clin Ultrasound 2009, 37:445-450.
39. Gannot G, Richardson AM, Rodriguez-Canales J, Pinto PA, Merino MJ, Chuaqui RF, Gillespie JW, Emmert-Buck MR: Decrease in CD8+ lymphocyte number and altered cytokine profile in human prostate cancer. Am J Cancer Res 2011, 1:120-127.

40. Rivera HM, Bethea $\mathrm{CL}$ : Ovarian steroids increase spinogenetic proteins in the macaque dorsal raphe. Neuroscience 2012, 208:27-40.

doi:10.1186/s12865-014-0042-3

Cite this article as: Chu et al:: Assessment of immune cells and function of the residual spleen after subtotal splenectomy due to splenomegaly in cirrhotic patients. BMC Immunology 2014 15:42.

\section{Submit your next manuscript to BioMed Central and take full advantage of:}

- Convenient online submission

- Thorough peer review

- No space constraints or color figure charges

- Immediate publication on acceptance

- Inclusion in PubMed, CAS, Scopus and Google Scholar

- Research which is freely available for redistribution 